УДК 343.9

DOI: $10.35750 / 2071-8284-2019-3-104-110$

\author{
А.Д. Рубан \\ адъюнкт \\ Санкт-Петербургский университет МВД России \\ Российская Федерация, 198206, г. Санкт-Петербург, ул. Лётчика Пилютова, д. 1 \\ ORCID: 0000-0002-9931-7926.E-mail: a_lisa13.13@mail.ru

\section{Правовые основы противодействия экстремистским проявлениям в период электоральных процессов}

\begin{abstract}
Аннотация: Противодействие экстремизму является одним из основных направлений государственной политики в сфере профилактики правонарушений. В период электоральных процессов частым и неизбежным явлением становится нарушение законодательства, в том числе уголовного. На страже законности и правомерности действий избирателей, кандидатов, избирательных объединений, избирательных комиссий и других участников выборов стоят нормы права, с помощью которых осуществляются защита и обеспечение субъективных избирательных прав граждан. В настоящей статье автор акцентирует внимание на особую актуальность деятельности уполномоченных органов по противодействию экстремистским проявлениям в период выборов с целью защиты основ конституционного строя и безопасности государств. Автором рассмотрены основные нормативные правовые акты, составляющие правовую основу в области противодействия экстремизму в период проведения избирательных кампаний. Проведён анализ отдельных положений нормативных правовых актов в области противодействия экстремистским проявлениям, в том числе в период выборов. В частности, обозначены наиболее значимые направления государственной политики в области защиты общества от деструктивного воздействия проявлений экстремизма. В результате анализа отдельных положений нормативных правовых актов автор приходит к выводу о необходимости совершенствования законодательства в этой сфере.
\end{abstract}

Ключевые слова: экстремистские проявления, экстремизм на выборах, противодействие экстремизму.

Для изитирования: Рубан А.Д. Правовые основы противодействия экстремистским проявлениям в период электоральных процессов // Вестник Санкт-Петербургского университета МВД России. - 2019. - № 3 (83). С. 104-110. DOI: 10.35750/2071-8284-2019-3-104-110.

\author{
Alisa D. Ruban \\ Graduate \\ Saint-Petersburg University of the MIA of Russia \\ 1, Letchika Pilyutova str., Saint-Petersburg, 198206, Russian Federation \\ ORCID: 0000-0002-9931-7926.E-mail: a_lisa13.13@mail.ru
}

\title{
Legal basis of tackling manifestations of extremism during the election process
}

\begin{abstract}
Annotation: Countering political extremism is one of the main tasks of state policy in the field of crime prevention. During the period of electoral processes, the violation of the law particularly criminal law becomes frequent and unavoidable. The rules of law guarantee the legality and legitimacy of voters, candidates, electoral associations, electoral commissions and other electoral participants actions. In this article, the author focuses on the special relevance of authorized bodies activities to counter political extremism during an election in order to protect the foundations of the constitutional system and states security. The author reviewed the main sources that form the legal basis for tackling extremism during the election campaigns. The analysis
\end{abstract}


of certain provisions of regulatory legal acts in the field of opposing of manifestations extremism including during the electoral period was done. In particular, the most strategic state policy for protecting society from destructive influence of extremism are discussed. Based on the analysis of some provisions of regulatory legal acts the author comes to the conclusion that it is necessary to improve legislation in this area.

Keywords: manifestations of extremism, election extremism, prevention extremism.

For citation: Ruban A.D. Legal basis of tackling manifestations of extremism during the election process // Vestnik of St. Petersburg University of the Ministry of Internal Affairs of Russia. - 2019. - № 3 (83). P. 104-110. DOI: 10.35750/2071-8284-2019-3-104-110.

Влияние выборов на жизнь современного государства носит чрезвычайно важный характер и проявляется во множестве их функций. Процесс, при котором происходят изменения в политической сфере, несёт в себе риск использования его в качестве подходящих условий для дестабилизации состояния безопасности общества и государства экстремистски настроенными элементами. В настоящее время такой деструктивной силой, несущей в себе угрозу для безопасности Российской Федерации и её народа, являются проявления экстремизма в период политических преобразований.

В современных условиях социальная база экстремизма количественно, по-видимому, определяется прежде всего социально-политической обстановкой как в стране в целом, так и в отдельных её регионах [1, с. 129].

Существующая тенденция распространения такого негативного явления, как экстремизм, представляющего собой угрозу не только для отдельных государств, но и для международной стабильности в целом, привела мировую общественность к выработке норм и принципов, направленных на урегулирование и стабилизацию отношений в этой сфере [2, с.100]. Впервые на международном уровне подобное явление получило нормативное закрепление в виде понятия «экстремизм» в Шанхайской конвенции о борьбе с терроризмом, сепаратизмом и экстремизмом (заключена в г. Шанхае 15 июня 2001 г.). В Российской Федерации необходимость разработки и развития законодательства в сфере противодействия экстремизму появилась в середине 90-х годов, вследствие произошедших массовых митингов и демонстраций, где имели место различные случаи проявлений радикальных настроений, массовых волнений и преступлений экстремистской направленности.

Электоральные события свидетельствуют о том, что экстремистские группировки различ- ного толка предпринимают попытки активно использовать выборы для насильственного изменения конституционного строя, насильственного захвата и насильственного удержания власти, нарушения территориальной целостности Российской Федерации, возбуждения ненависти либо вражды, унижения человеческого достоинства, массовых беспорядков и других противоправных действий [3, с. 24]. Непосредственно потенциальную угрозу представляют экстремистские организации, которые могут активизироваться в период предвыборной агитации и подготовки проведения выборов. В свою очередь, наиболее опасными видами экстремистской деятельности являются преступления экстремистской направленности, и, следовательно, их выявлению, раскрытию и расследованию постоянно должно уделяться повышенное внимание $[4$, с.186].

При этом цели при совершении преступлений экстремисткой направленности могут быть различны, например: влияние на явку избирателей; нарушение нормального хода подготовки, организации и проведения выборов; запугивание представителей органов власти. В качестве примера можно привести следующие события: убийство депутата Народного собрания Ислама Крымшамхалова, произошедшее 13 января 2009 г. за день до окончания регистрации кандидатов на выборах в парламент республики; убийство главы сельской администрации Абдулмуслима Нурмагомедова в Черкесске в селении Хаджалмахи Левашинского района 10 октября 2010 г., где проходили выборы в районное собрание депутатов, а также массовые беспорядки и кражу около 2 тыс. бюллетеней; деятельность российской общественно-политической межрегиональной организации националистическо-левого характера «Артподготовка», которая была признана экстремистской и запрещена на территории Российской Федерации. 
Немаловажно, что данную проблему озвучил Президент Российской Федерации В. В. Путин на расширенном заседании коллегии Министерства внутренних дел, которое было посвящено итогам оперативно-служебной деятельности органов внутренних дел за 2018 г. и планам работы на 2019 г. Как отметил В. В. Путин, одним из важнейших направлений работы становится противодействие экстремизму. При этом, он отметил, что несмотря на то, что общее число зарегистрированных преступлений экстремистской направленности в 2018 г. сократилось почти на $17 \%$, в разных формах и проявлениях такие преступления зарегистрированы практически в каждом субъекте Российской Федерации. Особое внимание, как подчеркнул в своем выступлении В. В. Путин, должно быть уделено: пресечению деятельности радикальных группировок посредством привлечения к этому общественности и органов власти, предупреждению конфликтов на этнической и религиозной почве, принятию решительных мер для выявления и последующего наказания тех, кто предпринимает попытки для распространения идеологии агрессии, насилия и нетерпимости, в том числе в молодёжной среде. Также Президент России отметил, что в целях профилактики этого вида преступлений необходимо максимально задействовать институты гражданского общества (религиозные, общественные организации и образовательные учреждения) ${ }^{1}$.

В Российской Федерации базовым документом стратегического планирования, который определяет национальные интересы и стратегические национальные приоритеты РФ, цели, задачи и меры в области внутренней и внешней политики, направленные на укрепление национальной безопасности РФ и обеспечение устойчивого развития страны на долгосрочную перспективу, является «Стратегия национальной безопасности Российской Федерации». В п. 17 Указа Президента Российской Федерации от 31 декабря 2015 г. № 683 «О Стратегии национальной безопасности Российской Федерации» (далее - Стратегия) законодатель указывает на позицию Запада, в которой усматривается направленность на противодействие интеграционным процессам и создание очагов напряжён-

\footnotetext{
${ }^{1}$ Расширенное заседание коллегии Министерства внутренних дел // Официальный сайт Президента России. - URL: http://kremlin.ru/events/president/news/59913 (дата обращения: 29.05.2019).
}

ности в Евразийском регионе, что, как следствие, оказывает отрицательное влияние на реализацию российских национальных интересов ${ }^{2}$. При этом отмечено, что позиция США и Европейского союза о поддержке антиконституционного государственного переворота, который произошел на Украине, привела к глубокому расколу в украинском обществе и возникновению вооружённого конфликта ${ }^{3}$. В п. 18 Стратегии выражена позиция законодателя по поводу тенденции свержения легитимных политических режимов, провоцирования внутригосударственной нестабильности и конфликтов, которая получает все более широкое распространение ${ }^{4}$.

В названном документе в качестве основных угроз государственной и общественной безопасности законодатель определяет следующие: 1) деятельность террористических и экстремистских организаций, которая направлена на насильственное изменение конституционного строя РФ и дестабилизацию работы органов государственной власти; 2) радикальные общественные объединения и группировки, которые в своей деятельности используют националистическую и религиозно-экстремистскую идеологию, 3) деятельность иностранных и международных неправительственных организаций, финансовых и экономических структур, в том числе частных лиц, направленную на нарушение единства и территориальной целостности РФ, а также на дестабилизацию внутриполитической и социальной ситуации в стране, включая инспирирование «цветных революций», разрушение традиционных российских духовнонравственных ценностей и др. ${ }^{5}$

Нормативно-правовое регулирование выборов в контексте противодействия экстремизму носит сложный характер и может быть представлено в виде системы. Так, установление оснований и мер юридической ответственности за нарушение именно положений законодательства о выборах и референдумах относится к ведению Российской Федерации, поскольку данный тезис находит отражение в ст. 79 (ответственность за нарушение законодательства Российской Федерации) Федерального закона от 12 июня 2002 г.

${ }^{2} \mathrm{O}$ Стратегии национальной безопасности Российской Федерации : Указ Президента РФ от 31 декабря 2015 № 683 // Собрание законодательства РФ. - 2016. - № 1 (часть II). - Ст. 212.

${ }^{3}$ Там же.

${ }^{4}$ Там же.

${ }^{5}$ Там же. 
№ 67-Ф3 «Об основных гарантиях избирательных прав и права на участие в референдуме граждан Российской Федерации», то есть данные отношения могут регламентироваться нормативными правовыми актами только в форме федерального закона. Исходя из этого, можно говорить о том, что за нарушение законодательства РФ о выборах и референдумах федеральными законами предусмотрено несколько видов юридической ответственности, а именно: конституционноправовая, административная и уголовная.

Например, конституционно-правовая ответственность за нарушение законодательства о выборах и референдумах состоит в применении к виновным участникам выборов (референдумов) определённых установленных законом санкций - таких как предупреждение; отказ в регистрации кандидата (списка кандидатов); отказ в регистрации инициативной группы по проведению референдума или иной группы участников референдума; отмена регистрации кандидата (списка кандидатов); отмена регистрации инициативной группы по проведению референдума или иной группы участников референдума; признание итогов голосования и результатов выборов, референдума недействительными и отмена соответствующего решения об итогах голосования (о результатах выборов, референдума); отмена решения о признании кандидата избранным и иные.

Непосредственно за административные правонарушения в сфере выборов (референдумов) наступает административная ответственность, предусмотренная Кодексом Российской Федерации об административных правонарушениях (ст. 5.1-5.25, 5.45-5.52, 5.56 КоАП РФ). Как правило, субъектами рассматриваемых административных правонарушений являются члены участковой комиссии (председатели, заместители председателей и секретари данных комиссий), в обязанности которых входит рассмотрение заявлений граждан.

Уголовная ответственность наступает за совершение общественно опасных деяний, направленных на нарушение прав граждан, причиняющих существенный вред охраняемым законом общественным отношениям при организации и проведении выборов (референдумов). К уголовно-правовым нормам, предусматривающим уголовную ответственность за подобные преступления, можно отнести: ст. 141 УК РФ (воспрепятствование осуществле- нию избирательных прав или работе избирательных комиссий); ст. $141^{1}$ УК РФ (нарушение порядка финансирования избирательной кампании кандидата, избирательного объединения, деятельности инициативной группы по проведению референдума, иной группы участников референдума); ст. 142 УК РФ (фальсификация избирательных документов, документов референдума); ст. $142^{1}$ УК РФ (фальсификация итогов голосования); ст. $142^{2}$ УК РФ (незаконные выдача и получение избирательного бюллетеня, бюллетеня для голосования на референдуме).

В первую очередь, говоря об ответственности за нарушения законодательства о выборах и референдумах в контексте противодействия экстремизму, нужно понимать, что такие нарушения носят разноплановый характер и могут быть классифицированы в зависимости от общественной опасности, субъекта, причинённого вреда и др.

Проявления экстремизма в ходе проведения выборов относятся к правонарушениям, непосредственно направленным на дестабилизацию состояния общественной безопасности, при этом цели, мотивы, способы и средства, как уже было отмечено, могут быть различными. Экстремистские проявления в период проведения выборов представляют собой насильственные действия, направленные на изменение государственной политики, конституционного строя государства и нарушение его территориальной целостности, посягающие на функционирование механизма государственной власти, общества в целом или на какие-либо его элементы, основанные на идеологии, оправдывающей совершение этих насильственных действий $[5$, с. 205]. Несмотря на то, что такие насильственные действия носят сложную и неоднородную форму выражения, зачастую их проведение в период выборов можно охарактеризовать как политический экстремизм.

В общем виде политический экстремизм можно охарактеризовать как доминирование определенных идеологических представлений о способах и средствах установления более справедливых социальных отношений между социальными субъектами общества (классами, большими социальными группами, их институтами) [6, с. 68].

К правовым основам противодействия экстремизму в период выборов, помимо названных нормативных правовых актов, целесообразно отнести такие, в которых законодатель непосредственно закрепил ограничения, запреты, 
влекущие определённую юридическую ответственность, за осуществление экстремистской деятельности. Прежде всего, правовую основу составляет Конституция РФ, предусматривающая равенство всех перед законом и судом, право на жизнь, право на свободу передвижения, свободу определения национальной принадлежности и пользование родным языком, свободу совести и вероисповедания, активное и пассивное избирательные права. Таким образом, с уверенностью можно говорить о том, что экстремистская деятельность направлена на нарушение большинства норм, предусмотренных гл. 1 и 2 Конституции РФ. Содержание понятия «основы конституционного строя» отражено в том числе в положениях Конституции РФ, где в главе 1 (ст. 1-16) «Основы конституционного строя» раскрываются его составляющие, которые, в свою очередь, представляют собой триаду ценностей «личность - общество - государство».

Экстремистские проявления в период проведения избирательных кампаний можно разделить на два вида - преступные и непреступные. К первой группе относятся деяния, ответственность за совершение которых предусмотрена УК РФ. Вторая группа включает в себя правонарушения, за совершение которых предусмотрена административная ответственность. Дальнейшая классификация каждого вида экстремистских проявлений предполагает выделение множества подвидов в зависимости от различных оснований, например, от направленности (на какие общественные отношения непосредственно посягает то или иное правонарушение); субъекта; умысла. Например, в УК РФ такие преступления включены в главу 29 «Преступления против основ конституционного строя и безопасности государства», в КоАП РФ правонарушения в этой сфере включены в главу 20 «Административные правонарушения, посягающие на общественный порядок и общественную безопасность». Препятствием на пути решения задач, прописанных в уголовном законе, является сложность в доказывании определённых видов преступлений, особенно преступлений экстремистской направленности [7, с. 50].

В Российской Федерации одним из основных нормативных правовых актов, составляющих правовую и организационную основу противодействия экстремистской деятельности, является Федеральный закон «О противодействии экстремистской деятельности» от 25 июля
2002 г. № 114-Ф3. В ст. 3 указанного закона закреплены основные направления противодействия экстремистской деятельности, а именно: 1) принятие профилактических мер, направленных на предупреждение экстремистской деятельности, в том числе на выявление и последующее устранение причин и условий, способствующих осуществлению экстремистской деятельности; 2) выявление, предупреждение и пресечение экстремистской деятельности общественных и религиозных объединений, иных организаций, физических лиц 6 . Под профилактикой экстремистской деятельности, согласно ст. 5 указанного закона, следует понимать осуществление в приоритетном порядке профилактических, в том числе воспитательных, пропагандистских мер, направленных на предупреждение экстремистской деятельности, федеральными органами государственной власти, органами государственной власти субъектов Российской Федерации, органами местного самоуправления в пределах своей компетенции ${ }^{7}$.

Данные положения коррелируют с предложенным в ст. 2 Федерального закона от 23 июня 2016 г. № 182-Ф3 «Об основах системы профилактики правонарушений в Российской Федерации» понятием «профилактика правонарушений», под которым понимается совокупность мер социального, правового, организационного, информационного и иного характера, которые направлены на: 1) выявление и устранение причин и условий, способствующих совершению правонарушений; 2) оказание воспитательного воздействия на лиц в целях недопущения совершения правонарушений или антиобщественного поведения ${ }^{8}$.

Прямые запреты на осуществление экстремистской деятельности содержатся в иных законах и подзаконных актах. Например, в соответствии с ч. 1 ст. 56 Федерального закона от 12 июня 2002 № 67-Ф3 «Об основных гарантиях избирательных прав и права на участие в референдуме граждан Российской Федерации» при проведении предвыборной агитации, агитации по вопросам референдума запрещается осуществлять

${ }^{6} \mathrm{O}$ противодействии экстремистской деятельности : Федеральный закон от 25 июля 2002 г. № 114-Ф3 // Собрание законодательства РФ. - 2002. - № 30. - Ст. 3031.

${ }^{7}$ Там же.

${ }^{8}$ Об основах системы профилактики правонарушений в Российской Федерации : Федеральный закон от 23 июня 2016 г. № 182-Ф3 // Собрание законодательства РФ. - 2016. № 26 (Часть I). - Ст. 3851. 
призывы к совершению деяний, определяемых в ст. 1 Федерального закона от 25 июля 2002 г. № 114-Ф3 «О противодействии экстремистской деятельности» как экстремистская деятельность, либо иным способом побуждать к таким деяниям, а также обосновывать или оправдывать экстремизм ${ }^{9}$ ст. 16 Федерального закона от 19 мая 1995 г. № 82-Ф3 «Об общественных объединениях» содержит запрет на создание (деятельность) общественных объединений, цели или действия которых направлены на осуществление экстремистской деятельности ${ }^{10}$; ч. 1 ст. 9 Федерального закона от 11 июля 2001 г. № 95-Ф3 «О политических партиях» содержит в себе указание на запрет создания и деятельности политических партий, цели или действия которых направлены на осуществление экстремистской деятельности ${ }^{11}$; Постановление Правительства РФ от 6 августа 2015 г. № 804 «Об утверждении Правил определения перечня организаций и физических лиц, в отношении которых имеются сведения об их причастности к экстремистской деятельности или терроризму, и доведения этого перечня до сведения организаций, осуществляющих операции с денежными средствами или иным имуществом, и индивидуальных предпринимателей». В качестве нормативного правового акта, регламентирующего деятельность по противодействию экстремистской деятельности на уровне субъекта Российской Федерации, можно назвать Закон Республики Дагестан от 4 марта 2016 г. № 20 «О профилактике экстремистской деятельности в Республике Дагестан».

Сегодня в противодействие экстремизму вовлечены как государственные, так и религиозные, общественные организации, однако пока нет единой правовой оценки данных явлений с учётом современных реалий, отсутствуют концептуальные позиции и меры реагирования на выявленные факты, а деятельность указанных организаций в основном сводится к представлениям отчётов, носящих общий статистический характер [8, с. 53].

\footnotetext{
${ }^{9}$ Об основных гарантиях избирательных прав и права на участие в референдуме граждан Российской Федерации : Федеральный закон от 12 июня 2002 г. № 67-Ф3 // Собрание законодательства РФ. - 2002. - № 24. - Ст. 2253.

${ }^{10}$ Об общественных объединениях : Федеральный закон от 19 мая 1995 г. № - 82-ФЗ // Собрание законодательства РФ. - 1995. - № 21. - Ст. 1930.

11 О политических партиях : Федеральный закон от 11 июля 2001 г. № 95-ФЗ // Собрание законодательства РФ. - 2001. - № 29. - Ст. 2950.
}

Одной из наиболее важных задач остается противодействие экстремизму в информационно-телекоммуникационной сети «Интернет». Данное направление является одним из актуальных направлений деятельности органов государственной власти и правоохранительных органов на современном этапе [9, с.144].

Таким образом, правовые основы противодействия экстремизму (экстремистской деятельности) можно определить как общепризнанные принципы и нормы международного права, международные договоры РФ, федеральные законы, нормативные правовые акты Президента РФ и Правительства РФ, а также принимаемые в соответствии с ними нормативные правовые акты других федеральных органов государственной власти.

Результаты анализа международного и национального опыта в сфере противодействия экстремизму демонстрируют необходимость принятия следующих мер, которые зарекомендовали себя как наиболее эффективные в этой области: совершенствование правовой базы; укрепление и совершенствование деятельности правоохранительных органов и специальных служб; усиление контроля в области финансирования экстремизма и терроризма; активизация деятельности, направленной на разъяснительную и пропагандистско-идеологическую работу, особенно в молодёжной среде.

Как справедливо отмечает А. В. Петров, в целях профилактики и недопущения распространения экстремистских проявлений от всех субъектов, в компетенцию которых включена деятельность по профилактике преступности, требуется комплексный подход к осуществлению противодействия, включающего в себя меры регулирующего, запретительного и профилактического характера [10, с.164].

На современном этапе развития общества средства и методы субъектов, имеющих пассивное или активное избирательное право, для достижения преступных целей с каждым днем совершенствуются и видоизменяются. Необходимо иметь в виду, что для выявления потенциально опасных угроз безопасности государства, важно не ограничиваться нормами, которые содержат в себе уголовную и иную юридическую ответственность, но и видеть те негативные явления, за которые в настоящий момент юридическая ответственность, не предусмотрена, но в перспективе неизбежна. 


\section{Список литературь}

1. Ильччёв И. Е., Лазарева С. А. О понятии и классификации проявлений экстремизма // Вестник Казанского юридического института МВД России. - 2017. - № 3 (29). - С. 126-133.

2. Колов А. М. Пределы экстремизма и правовые основы противодействия его проявлениям // Бизнес в законе. - 2010. - № 3. - С. 100-104.

3. Красинский В. В. Правовое регулирование выборов в контексте противодействия политическому экстремизму в Российской Федерации // Военно-юридический журнал. - 2006. - № 5. - С. 24-29.

4. Коршунова О. Н. Влияние особенностей механизма преступлений экстремистской направленности на предмет доказывания по уголовным делам // Вестник ОмГУ. - Серия «Право». - 2018. № 1 (54). - С. 186-191.

5. Ерёмин Д. Н. Особенности осуществления оперативно-розыскной деятельности по делам о преступлениях, связанных с политическим экстремизмом // Вестник Чеченского государственного университета. - 2015. - №. 2. - С. 205-208.

6. Гайворонская А. А. Моделирование психосемантики политического экстремизма // Вестник Удмуртского университета. - Серия «Философия. Психология. Педагогика». - 2017. - № 1. - С. 66-71.

7. Васкэ Е. В., Горюнова-Куракина О. И. Проблемы доказывания умысла при расследовании преступлений экстремистской направленности (на примере ст. 282 УК РФ) // Приволжский научный вестник. - 2014. - № 12-2 (40). - С. 50-55.

8. Кочесокова 3. Х., Яхьяев Т. Л. Некоторые аспекты взаимодействия в противодействии преступлениям экстремистской направленности // Пробелы в российском законодательстве. - 2017. - № 3. - C. 52-54.

9. Троегубов Ю. Н. Проблемы противодействия экстремизму в сети Интернет // Гуманитарный вектор. - Серия «История, политология». - 2014. - № 3 (39). - С. 143-147.

10. Петров А. В. Экстремизм: понятие и виды в современной России // Гуманитарные, социальноэкономические и общественные науки. - 2015. - № 4. - С. 160-164.

\section{References}

1. Il 'ichyov I. E., Lazareva S. A. O ponyatii i klassifikacii proyavlenij e'kstremizma // Vestnik Kazanskogo yuridicheskogo instituta MVD Rossii. - 2017. - № 3 (29). - S. 126-133.

2. Kolov A. M. Predely` e'kstremizma i pravovy'e osnovy protivodejstviya ego proyavleniyam // Biznes v zakone. - 2010. - № 3. - S. 100-104.

3. Krasinskij V. V. Pravovoe regulirovanie vy'borov $\mathrm{v}$ kontekste protivodejstviya politicheskomu e`kstremizmu v Rossijskoj Federacii // Voenno-yuridicheskij zhurnal. - 2006. - № 5. - S. $24-29$.

4. Korshunova O. N. Vliyanie osobennostej mexanizma prestuplenij e 'kstremistskoj napravlennosti na predmet dokazy`vaniya po ugolovny`m delam // Vestnik OmGU. Seriya «Pravo». - 2018. - № 1 (54). - S. 186-191.

5. Eryomin D. N. Osobennosti osushhestvleniya operativno-rozy'sknoj deyatel'nosti po delam o prestupleniyax, svyazanny'x s politicheskim e'kstremizmom // Vestnik Chechenskogo gosudarstvennogo universiteta. - 2015. - №. 2. - S. 205-208.

6. Gajvoronskaya A. A. Modelirovanie psixosemantiki politicheskogo e'kstremizma // Vestnik Udmurtskogo universiteta. Seriya «Filosofiya. Psixologiya. Pedagogika». - 2017. - № 1. - S. 66-71.

7. Vaske' E. V., Goryunova-Kurakina O. I. Problemy' dokazy`vaniya umy'sla pri rassledovanii prestuplenij e'kstremistskoj napravlennosti (na primere st. 282 UK RF) // Privolzhskij nauchny`j vestnik. 2014. - № 12-2 (40). - S. 50-55.

8. Kochesokova Z.X., Yax'yaev T. L. Nekotory`e aspekty` vzaimodejstviya v protivodejstvii prestupleniyam e’kstremistskoj napravlennosti // Probely` v rossijskom zakonodatel`stve. - 2017. - № 3. - S. 52-54;

9. Troegubov Yu. N. Problemy 'protivodejstviya e'kstremizmu v seti Internet // Gumanitarny’j vektor. Seriya: Istoriya, politologiya. - 2014. - № 3 (39). - S. 143-147.

10. Petrov A. V. E'kstremizm: ponyatie i vidy' v sovremennoj Rossii // Gumanitarny'e, social'noe`konomicheskie i obshhestvenny`e nauki. - 2015. - № 4. - S.160-164.

(с) Рубан А.Д., 2019

Статья поступила в редакцию 15.06.2019 г. 